\title{
Aprendizagem docente do formador: os sentidos na e da docência no contexto do trabalho pedagógico no ensino superior
}

\author{
Sybelle Regina Carvalho Pereira* \\ Doris Pires Vargas Bolzan ${ }^{* *}$ \\ Vanessa Sandri**
}

\section{Resumo}

Neste artigo, discute-se a aprendizagem docente na educação superior, analisada a partir da dimensão categorial dos sentidos produzidos no contexto profissional. Como objetivo, buscou-se compreender os sentidos produzidos na e da docência no contexto do trabalho pedagógico. Os participantes são docentes dos cursos de licenciatura em Pedagogia (diurno e noturno) de uma instituição de ensino superior pública. Esta investigação qualitativa foi desenvolvida a partir da abordagem narrativa sociocultural. No processo de análise dos achados, identificaram-se os sentidos construídos, que indicam que a aula universitária constitui-se em um lugar de aprendizagem dinamizado pelas relações interpessoais; pelo (re)conhecimento do contexto social e cultural do estudante, o que implica na reflexão acerca da organização pedagógica do ensino, e pelas ações auto e interformativas vividas pelos formadores, originadas pela ideia de inacabamento, uma vez que são sujeitos ensinantes e aprendentes. Compreende-se que tanto os formadores como as instituições de ensino superior necessitam planejar as atividades formativas, considerando a tessitura dos significados compartilhados e os sentidos subjetivados nas relações pedagógicas vividas nos processos de ensino e de aprendizagem. Esses sentidos configuram-se em indicadores que repercutirão na sistematização e criação de processos formativos contextualizados em redes colaborativas a fim de favorecer o desenvolvimento profissional docente.

Palavras-chave: Aprendizagem docente. Desenvolvimento profissional. Educação superior. Trabalho pedagógico.

\author{
Recebido: 26/04/2016 - Aprovado: 30/06/2016 \\ http://dx.doi.org/10.5335/rep.v23i2.6543
}

\begin{abstract}
Professora da Universidade de Passo Fundo. Doutoranda do Programa de Pós-Graduação em Educação da Universidade Federal de Santa Maria. E-mail: sybelleregina@gmail.com

** Professora do Programa de Pós-Graduação em Educação da Universidade Federal de Santa Maria. Doutora em Educação pela Universidade Federal do Rio Grande do Sul. E-mail: dbolzan19@gmail.com

*** Doutoranda do Programa de Pós-Graduação em Educação da Universidade Federal de Santa Maria. E-mail: vanesandri@yahhoo.com.br
\end{abstract}




\section{Apresentação da temática}

Argumentamos que a docência universitária pressupõe do formador a apropriação dos saberes implicados nas ações e na organização do trabalho docente, $o$ qual é compreendido como uma forma particular de atividade sobre o humano em que o trabalhador se dedica ao seu "objeto" de trabalho, que é, justamente, outro ser humano, no modo fundamental da interação humana (TARDIF; LESSARD, 2013). Isso significa que a docência demanda tanto a assimilação dos saberes ${ }^{1}$ disciplinares e curriculares como dos saberes experienciais envolvidos na cultura institucional. Portanto, é na articulação entre esses saberes que se constroem os saberes pedagógicos, ${ }^{2}$ que repercutirão sobre os processos de organização e criação na atividade de ensino.

Em meio a esses elementos que envolvem a docência no ensino superior, pode-se afirmar que os estudos no campo da pedagogia universitária reforçam a necessidade da construção de aportes teóricos e metodológicos que subsidiem a consolidação de ações formativas institucionais, e favoreçam a construção da docência e fomentem o desenvolvimento profissional docente (DPD) de professores/formadores no âmbito das instituições de ensino superior (IES) (ALMEIDA, 2012; CUNHA, 2010, 2014; ISAIA, BOLZAN, 2009a, 2009b; PIMENTA; ANASTASIOU, 2014).

Nessa direção, apresentamos uma pesquisa que tem como foco principal estudar a aprendizagem da docência do professor universitário, uma das temáticas desenvolvidas pelo grupo de pesquisa Formação de Professores e Práticas Educativas: educação básica e superior, especificamente relacionada ao estudo interinstitucional e integrado, designado "Aprendizagem da docência: processos formativos de estudantes e formadores da educação superior", ${ }^{3}$ cujo objetivo consistiu em compreender as concepções sobre a aprendizagem docente dos estudantes e dos professores/formadores das licenciaturas e como essas concepções implicam nos processos formativos da docência. Foram participantes dessa investigação professores formadores e estudantes dos cursos de Pedagogia e Educação Especial de duas IES, uma pública, outra comunitária.

Assim, este artigo constitui-se em um recorte da investigação principal, no qual se apresenta, especificamente, a análise da dimensão categorial dos sentidos produzidos no contexto da profissão docente dos cursos de licenciatura em Pedagogia diurnos (PD) e noturnos (PN) de uma IES pública. Dessa forma, o objetivo é compreender a produção de sentidos na e da docência no contexto do trabalho pedagógico ${ }^{4}$ nos respectivos cursos.

Concebemos que os significados e sentidos que compõem a docência são tecidos na prática cotidiana do ofício do educador, assim como nas ações formativas, 
desenvolvidas na realidade institucional e pelas quais o professor, individual ou coletivamente, dá início a um processo de aprendizagem que o coloque em condições de desenvolver a sua prática profissional. Portanto, compreendemos os processos formativos identificados como uma dinâmica complexa movimentada, primeiramente, por uma necessidade que se amplia e qualifica por meio de contextos de aprendizagem colaborativos, capazes de promover o alcance dos objetivos pessoais e profissionais (BOLZAN et al., 2013; BOLZAN et al., 2014; BOLZAN et al., 2016; FERRY, 2008; VAILLANT; MARCELO, 2012).

Logo, a aprendizagem de ser professor relaciona-se aos processos formativos vivenciados ao longo da trajetória pessoal e profissional, mobilizados pelos desafios e pelas exigências do contexto de atuação docente, que impulsionam os professores a reverem, constantemente, sua formação. Para Bolzan et al., a aprendizagem docente consiste em um processo que se caracteriza pelos "modos de construção e produção da docência, ou seja, os modos de aprender e se fazer professor. É um processo organizado por meio de movimentos oscilatórios" (2013, p. 10). Esse processo caracteriza-se por avanços e retrocessos e pelo permanente inacabamento, dinamizado, em um primeiro momento, por uma necessidade de autoformação ${ }^{5}$ fortalecida pelas ações interformativas, ${ }^{6}$ constituindo-se em redes de aprendizagem.

A construção das redes caracteriza-se por um movimento dialético de relação inter e intrapessoal, ou seja, em uma relação arquitetônica, ${ }^{7}$ que se caracteriza pelo sentido atribuído ao que é aprendido na convivência com o outro em um ato-evento singular e situado. Assim sendo, o outro é alguém que nos responde, alguém que nos constitui e que, no processo da relação vivida, também passa a ser constituído por nós, o que implica reconhecer a alteridade como uma particularidade humana. Ao conviver com o outro, o professor compartilha significados sociais e constrói sentidos que se transformam ao longo da formação inicial e da sua carreira profissional (BAKHTIN, 2011, 2012a; PONZIO, 2012; SOBRAL, 2010a, 2010b; VYGOTSKI, 1994, 1995, 2009).

Portanto, ao olharmos para o movimento de aprender a docência, é imprescindível que se pense em uma docência universitária contextualizada, que repercute na reflexão sobre a intervenção didático-pedagógica do professor, no papel e na função mediadora do docente na organização do ensino e nos sentidos elaborados pelos formadores sobre a sua professoralidade ${ }^{8}$ ao longo do seu processo formativo.

A complexidade da docência na educação superior e a ausência de formação prévia e específica para atuar como docente, sobretudo a ausência de uma formação pedagógica e didática, trazem dificuldades para o cumprimento do papel do professor formador. Nessa perspectiva, alguns desafios se colocam para que possamos compreender a formação pedagógica como um ponto crucial no processo formativo 
do professor universitário (CUNHA, 2010, 2014; ISAIA; BOLZAN, 2007a, 2007b, 2009a; PIMENTA; ANASTASIOU, 2014).

Em primeiro lugar, há que se superar a crença de que ser titulado como mestre e doutor, por si só, promove a competência, tanto para a pesquisa como para o ensino. Do mesmo modo, há que se refutar a ideia de que ter muitos anos de experiência profissional significa a existência de um saber pronto e acabado. Essa concepção vai de encontro ao sentido de inacabamento no processo formativo. Tais aspectos colaboram intensamente para a (des)profissionalização do professor no tocante à crença de que a formação tem pouco impacto na qualificação do saber e no fazer pedagógico (IMBERNÓN, 2011).

Logo, a formação docente consiste em um processo complexo caracterizado por diversos enfrentamentos, desafios e exigências que singularizam a docência e o desenvolvimento profissional docente desses sujeitos, constituindo-se por um movimento colaborativo e compartilhado, no qual se entrelaçam as histórias de vida pessoal e profissional.

De acordo com Isaia e Bolzan:

[...] na dimensão pessoal, a marca está na construção da subjetividade decorrente do modo como os professores e o mundo se interpenetram, influenciando-se mutuamente. Já na dimensão profissional o característico está no modo dos professores transitarem em um ou vários espaços institucionais e irem pouco a pouco se inteirando do saber fazer, próprio da profissão (2009b, p. 122).

Nesse contexto, as dimensões pessoal e profissional implicam a compreensão de que as trajetórias formativas dos docentes estão condicionadas às suas histórias de vida e ao modo como, ao longo da carreira, eles aprendem e enfrentam os desafios da docência na educação superior. Ao refletir sobre esses elementos, o formador consegue tomar consciência sobre os saberes apreendidos nas experiências cotidianas e, assim, constituir o seu percurso na aprendizagem de ser professor (GARCIA, 1999; ISAIA; BOLZAN, 2007b, 2009a; ISAIA, 2009; HUBERMAN, 2000; NÓVOA, 2000). Segundo Bolzan e Isaia, a aprendizagem docente caracteriza-se pela perspectiva:

[...] colaborativa, faz-se na prática de sala de aula e no exercício de atuação cotidiana da universidade. É uma conquista social, compartilhada, que envolve trocas e representações. Com essa postura, o professor está produzindo sua professoralidade, o que implica não só em dominar conhecimentos, saberes, fazeres de determinado campo, mas também na sensibilidade em termos de atitudes e valores que levem em conta os saberes da experiência. Esta, contudo, precisa ser entendida, a partir de uma ótica de reflexão sistemática na qual o foco está nas relações interpessoais, componente intrínseco ao processo de ensinar, aprender, formar-se e, consequentemente, desenvolver-se profissionalmente (2010, p. 16). 
Esses aspectos demonstram a intensa atividade interpessoal, via redes de interação, e a mediação vivida no espaço e no tempo da aula, demonstrando que a formação do professor é também interformação, pois se (re)constrói na relação social, implicando uma aprendizagem que se dá em uma relação de colaboração e reciprocidade e, assim, contribui qualitativamente para o desenvolvimento profissional docente.

Contudo, outros aspectos estão envolvidos e interferem para que o desenvolvimento profissional tenha um impacto positivo na carreira do professor, entre eles: políticas públicas afinadas com as necessidades contextuais da educação brasileira, remuneração e condições dignas de trabalho, incentivo à autonomia na tomada de decisões, planos de carreira que valorizem os esforços individuais e coletivos de desenvolvimento profissional docente, um ambiente de trabalho acolhedor, entre outras condições. Tais fatores precisam ser considerados em uma totalidade, pois serão articulados com as ações formativas que potencializarão a (re)construção da profissão (CUNHA, 2014; IMBERNÓN, 2009, 2011).

Dessa forma, compreendemos que o desenvolvimento profissional docente torna-se viável não só a partir do movimento autoformativo, como também a partir da implementação de ações institucionais que promovam espaços nos quais os professores possam se engajar, interagir e desenvolver os saberes próprios do ofício docente.

No entanto, destacamos que um professor iniciante pode desenvolver sentimentos de angústia, solidão e desânimo diante dos desafios educativos que se apresentam, assim como um professor próximo da aposentadoria pode sentir-se desgastado pelos anos de atuação na profissão e estar enfrentando essa fase do ciclo vital sem o apoio adequado para refletir sobre o novo tempo de vida. Acreditamos que, para auxiliar o professor ao longo da sua trajetória profissional, é necessário criar redes colaborativas, a fim de se promover a construção de um conhecimento que possa ser compartilhado e provoque aprendizagens significativas que deem sentido e direcionamento às decisões a serem tomadas nos diversos períodos da carreira docente (BOLZAN; POWACZUK, 2013; ISAIA; BOLZAN, 2007a, 2009b).

\section{0 estudo}

Compreendemos que a pesquisa em ciências humanas encontra seu principal tema de estudo ao explicar o mundo dos homens. Para isso, faz-se fundamental almejar compreender o seu viver, seus processos de interação, suas atitudes éticas, seu esforço teórico empreendido para o entendimento de um fenômeno assim como o sentido de seus atos, responsivamente, situados em um contexto histórico, cul- 
tural e institucional. Ao assumir essa concepção, estamos nos vendo como pesquisadores que dialogam com a sua própria singularidade e a de seus colaboradores. Vemos a pesquisa como um encontro com o outro, o que implica um movimento de alteridade (AMORIM, 2004, 2009; BAKHTIN, 2011, 2012a; MARTINS FIGHERA; BOLZAN, 2014; SOBRAL, 2010a, 2010b).

A totalidade de sentido, de valor nas relações vividas representa a essência do plano estético, o qual se sustenta na relação de alteridade. É no diálogo com o outro que constituímos nossa subjetividade, identidade, e formamos nossa consciência. Nesse sentido, Amorim nos auxilia a compreender o papel fundamental da alteridade na pesquisa em ciências humanas:

Nossa hipótese de trabalho é de que em torno da questão da alteridade se tece uma grande parte do trabalho do pesquisador. Análise e manejo das relações com o outro constituem, no trabalho de campo e no trabalho da escrita, um dos eixos em torno dos quais se produz o saber. Diferença no interior de uma identidade, pluralidade na unidade, o outro é ao mesmo tempo aquele que quero encontrar e aquele cuja impossibilidade de encontro integra o próprio princípio da pesquisa. Sem reconhecimento da alteridade não há objeto de pesquisa, e isto faz com que toda a tentativa de compreensão e de diálogo se construa sempre na referência aos limites dessa tentativa (2004, p. 28).

Cabe salientar que, nessa concepção de investigação, faz-se necessário que o pesquisador se situe em um tempo e espaço singular, ou seja, em um outro lugar, diferente do seu interlocutor, para que assim consiga olhar os discursos e completar o horizonte dos sentidos produzidos no diálogo com os sujeitos da investigação pelo excedente da sua visão ${ }^{9}$ sobre o tema. Tal lugar é condicionado pela sua insubstituibilidade e pela responsividade em um evento. Dimensões que o comprometem a considerar o outro como alguém que produz o seu saber ao interagir com os significados históricos e sociais, imprimindo os sentidos a suas atividades e ações profissionais.

O estudo, que ora apresentamos, foi desenvolvido a partir da abordagem qualitativa de cunho sociocultural narrativo. Essa concepção revelou-se a mais coerente com a pesquisa, por compreender que o professor se (trans)forma nas redes de relações que estabelece no seu cotidiano e nas atividades de estudos que desenvolve. Dessa forma, as múltiplas vozes dos formadores foram ouvidas, representando um importante elemento para a reflexão e a aprendizagem compartilhada, tendo em vista os sentidos da e na docência produzidos e implicados no processo de aprender a ser professor na educação superior.

Esta investigação foi realizada em uma IES pública, de estrutura multicampi, localizada na região central do estado do Rio Grande do Sul, que desenvolve suas finalidades educativas com base na indissociabilidade entre ensino, pesquisa e extensão. Sua estrutura organizacional e pedagógica envolve os níveis de edu- 
cação básica e superior distribuídos em quinze unidades universitárias. Essa instituição configura-se como uma universidade de grande porte e atende cerca de 26 mil estudantes, com um quadro de, aproximadamente, 4.200 servidores, entre docentes, técnicos, tecnólogos e funcionários técnico-administrativos em educação. Desenvolve e representa importante função social na comunidade regional e nacional ao promover a formação científica, tecnológica, cultural e cidadã dos futuros profissionais que atenderão as demandas sociais e científicas do país. Dois cursos de licenciatura em pedagogia fazem parte do nosso estudo, um se desenvolve no período diurno e o outro no noturno.

Participaram desta pesquisa formadores que atuam como docentes nesses cursos vinculados aos departamentos didáticos: Administração Escolar, Educação Especial, Fundamentos da Educação e Metodologia do Ensino. Observamos que $80 \%$ dos formadores apresentam como titulação acadêmica o doutorado; $50 \%$ dos docentes no curso PD e 57\% no curso PN são formados em pedagogia; $94 \%$ dos docentes do PD e $71 \%$ dos docentes do PN estão envolvidos com projetos de pesquisa; mais de $50 \%$ dos professores vivenciaram, não concomitantemente, por mais de quinze anos a docência na educação básica e também na educação superior, portanto, encontram-se em uma fase da vida profissional que se caracteriza pelo predomínio de atitudes de autonomia e diversificação com relação às atividades didático-pedagógicas e científicas (HUBERMAN, 2000; ISAIA, 2009).

Utilizamos, para a coleta de dados, a análise documental e a entrevista narrativa semiestruturada. A análise documental foi implementada no sentido de mapearmos o contexto sociocultural da pesquisa. Para isso, analisamos o currículo Lattes dos docentes a fim de conhecermos suas trajetórias formativas e os projetos político-pedagógicos, no sentido de compreendermos os objetivos, o perfil do egresso, os princípios pedagógicos, a matriz e a dinâmica curricular dos cursos, para assim construirmos uma visão panorâmica da conjuntura institucional e pedagógica na qual o formador desenvolve o seu trabalho docente. Desse modo, foi possível estabelecer um diálogo com os professores participantes e complementar os achados que emergiram das entrevistas narrativas (LÜDKE; ANDRÉ, 2013).

As entrevistas narrativas semiestruturadas nos propiciaram escutar os sujeitos da investigação, construindo um espaço de interlocução ao considerar o formador como autor da sua história e capaz de contá-la a alguém (aos pesquisadores), reconstruindo os acontecimentos vividos ao longo da sua trajetória pessoal e profissional e conferindo-lhes sentido valorativo, na sua singularidade (BAKHTIN, 2011; JOVCHELOVITCH; BAUER, 2014). Os processos formativos da docência (trajetórias pessoal e profissional), as atividades docentes de estudo e de pesquisa, 
as concepções pedagógicas e as organizações e ações desenvolvidas no trabalho pedagógico foram os tópicos que guiaram o roteiro da entrevista.

Segundo Bolzan, é na tessitura das narrativas que se reconstroem os saberes, as habilidades e as atitudes de forma compartilhada. Na expressão da autora:

[...] esses discursos, por sua vez, servem de influência social para o pensamento. Assim, podemos dizer que todo o ato de fala sobre um entendimento comum pode tornar evidente a compreensão do outro. [...] No transcorrer de uma conversação, os indivíduos têm oportunidade de dizer tanto seus entendimentos, quanto seus mal-entendidos. A possibilidade de colocar o pensamento em palavras favorece ao indivíduo a conscientização de sua compreensão, ou não, sobre os temas em discussão, além de favorecer que um elemento do grupo sirva de estímulo auxiliar, criando-se oportunidade de esclarecer e discutir os temas obscuros para os indivíduos no grupo (2009a, p. 13-14).

Nessa perspectiva, ressaltamos que a palavra está carregada de sentido ideológico e vivencial, que, ao ser compartilhado no processo de interlocução, de diálogo, influencia na construção do pensamento. O homem constitui-se como humano no processo de interação social mediado pela linguagem. Esse instrumento cultural auxilia o sujeito a desenvolver e a compreender as formas coletivas e singulares de perceber e organizar o mundo real (BAKHTIN, 2012b).

Assim, destacamos que a abordagem sociocultural assume grande importância, possibilitando a construção de fundamentos teóricos que problematizem a práxis pedagógica dos docentes, no sentido de compreender o modo como esses sujeitos vivenciam e elaboram os seus processos de formação e de aprendizagem e, consequentemente, como esses repercutem em ações gerativas capazes de colaborar na produção da docência.

Realizamos a dinâmica da análise dos achados a partir do trabalho coletivo e compartilhado no grupo de pesquisa. Primeiramente em pequenos grupos de pesquisadores, após, no coletivo, quando as interpretações foram discutidas e problematizadas, promovendo uma análise ampla sobre as categorias, dimensões categoriais, recorrências e evidências narrativas que emergiram dos discursos dos entrevistados.

Assim, a aprendizagem docente e os processos formativos constituíram-se em categorias de análise da investigação. Dentre as dimensões que articulam essas categorias, estão a arquitetura de formação proposta pelas dinâmicas institucional e pedagógica, a concepção de formação sugeridas pelas atividades docente e discente de estudo e a produção de sentido da e na docência, indicada pelas trajetórias formativas e pela profissão em contexto. As evidências narrativas identificadas na pesquisa demonstram que as interações entre a aprendizagem docente e os processos formativos apresentam fronteiras permeáveis e relacionais entre as três dimensões categoriais, caracterizando-se por uma articulação interna que se cons- 
titui de uma unidade advinda do sentido que se compôs pelo processo de subjetivação construído, a partir das experiências e das vivências socioculturais (BOLZAN et al., 2016).

Essa articulação, ainda, caracteriza-se a partir dos seguintes aspectos: a coerência interna da unidade entre teoria e prática, a consciência do inacabamento, as exigências e os desafios da profissão docente, compreendidos como um ato-evento ${ }^{10}$ social e responsável, e pela dinâmica espiralada que movimenta as categorias investigadas. Neste artigo, destacamos a dimensão de produção de sentidos da e na docência constituída pelas vivências socioculturais no âmbito da IES.

\section{Um recorte da análise: ${ }^{11}$ a produção de sentidos da e na docência no contexto do trabalho pedagógico}

Ao narrar suas trajetórias formativas, os professores objetivam os sentidos e trazem as aprendizagens vivenciadas implicadas e dinamizadas no cotidiano do trabalho docente. Tais vivências, representadas pelas exigências e pelos desafios do contexto sociocultural e institucional, estabelecem diferentes matizes na formação docente, que são, predominantemente, marcadas pelo coletivo e, dialeticamente, constituídas pelos sentidos construídos no âmbito do trabalho pedagógico.

Portanto, consideramos que a produção de sentido, na contextura do trabalho pedagógico, refere-se ao modo como é atribuído valor sobre os elementos da prática e da teoria que constituem a docência e que repercutem no processo de aprender a ser professor. Essa dimensão desdobra-se em ações que se constituem nas vivências formativas e na opção pela docência, interseccionadas pelos desafios e exigências do formador no cotidiano do trabalho docente, o que permite refletir sobre as atividades e ações que caracterizam o processo de ensino e de aprendizagem experimentado no cotidiano da profissão (BOLZAN; POWACZUK, 2015, p. 203).

Cabe esclarecer que o sentido é concebido como expressão emotivo-volitiva, produzida a partir do encontro com o outro em um evento, nesse caso, a aula, considerado na sua concretude histórica. Os sentidos constituem-se a partir dos significados produzidos na cultura socialmente acumulada. Enquanto o sentido é a parte mais maleável de um tema por estar vinculado à subjetividade das pessoas que vivem determinado ato-evento, o significado é o que se mantém perene em um conceito ou ideia (BAKHTIN, 2012a; VYGOTSKI, 2009).

Com o objetivo de promover a reflexão sobre a aprendizagem de ser professor na educação superior, buscamos compreender os eventos, os desafios e as exigências vividos no contexto da profissão, no âmbito da universidade, e que marcam o 
trabalho pedagógico repercutindo singularmente nas suas trajetórias formativas e no desenvolvimento profissional.

Na produção de sentidos, temos a opção pela docência marcada pela subjetividade, representada na dimensão pessoal, que singulariza o percurso formativo docente vivenciado. A trajetória pessoal marca a construção subjetiva do professor quanto à desenvoltura do seu ciclo vital, considerando que as marcas da vida configuram o ser professor, tornando-se elementos constitutivos da formação e do desenvolvimento profissional (ISAIA, 2006, p. 368).

No caso dos formadores participantes desta pesquisa, a escolha constituiu-se a partir das relações vividas na família e na escola, direcionadas, primeiramente, para a atuação na educação básica. A nosso ver, assumir essa escolha profissional identifica os formadores, uma concepção de vida, mundo e valores, que influenciam as decisões formativas e de orientação pedagógica tomadas ao longo da carreira.

Podemos dizer, portanto, que as ações e operações produzidas ao longo da trajetória pessoal e profissional indicam a escolha da profissão, como evidenciam as narrativas a seguir:

Eu sou filha de professora então, eu acho que eu fui constituída professora na barriga da minha mãe, porque a mãe ia (eu digo isso no meu memorial) para a PUC de Uruguaiana, no tempo que as estradas eram de chão, naquele regime especial do curso de Pedagogia. Ela era professora estadual em São Vicente do Sul e pegava o ônibus, virava a noite para chegar em Uruguaiana e desenvolver o curso dela. Ela estava grávida de mim [...]. Então, inicio a minha trajetória profissional no final da década de 80, no município de Santa Maria como professora municipal (Professora Emília).

Eu respirei muito a escola desde a minha infância. Sou filha de professora. Isso para mim é um dado fortíssimo. Porque ter sido filha de professora representava não estar na escola somente nos espaços que eu tinha aula. Representava estar nos espaços onde a minha mãe trabalhava como professora. Nas reuniões pedagógicas, porque a gente estava por ali. Então, nós vivíamos a escola, e viver a escola era uma questão muito importante. A mãe saía (sala de aula) e eles adoravam puxar a filha da professora, para baixo, para cima, então teve momentos que eu fui a aluna delas, teve momentos que eu fui a professora (Professora Rosa).

[...] fui alfabetizador de adultos em 1976, era um projeto que estava engatinhando no método Paulo Freire, era uma adaptação, que na realidade foi um padre amigo meu que me convidou, o método SDB. SDB é Dom Bosco, essa legenda, Dom Bosco é uma ordem religiosa da Igreja Católica, mesmo não sendo religioso, era muito amigo desse padre. Então ele me convidou, fiz o curso e acabamos com outras duas moças, na época, alfabetizando adultos aqui em Santa Maria. [...] isso foi referência, aquilo que me moveu a me decidir por ser professor (Professor Igor).

A pertinência em conhecer os aspectos que determinam a opção pela docência refere-se ao fato de que olhar as histórias vividas pelos sujeitos pode auxiliar no entendimento dos referenciais que os professores têm de si mesmos e que incidem 
na construção da profissão e no enfrentamento dos desafios e dilemas da carreira profissional. As imagens e crenças que são subjetivadas ao longo das experiências vividas influenciam a orientação pedagógica sob a prática da docência, assim como constituem os pilares da tomada de decisões e consciência sobre si e sobre a docência ao longo da sua trajetória formativa.

Essa análise enseja-nos a refletir sobre a construção da identidade do professor, compreendida como um processo que se constrói nas interações vivenciadas com o outro e decorre da "significação social da profissão, do confronto entre teorias e práticas, e dos modos que cada professor, enquanto ator e autor confere à sua atividade docente cotidiana com base em sua história de vida" (PIMENTA; ANASTASIOU, 2014, p. 77). Nesse contexto, o professor constrói os saberes e fazeres da docência entrelaçando as dimensões pessoais e profissionais que constituem a base epistemológica que fundamenta suas ações.

Identificamos que o diálogo, a convivência e o apoio ao outro aparecem de forma recorrente nas narrativas, ressaltando que a totalidade de conteúdo dos discursos identifica que a concepção de ensinar valora as relações interpessoais vividas no cotidiano, como a essência do sentido ético e estético, o qual se sustenta na relação de alteridade na docência. Essa relação está expressa nas seguintes narrativas:

Nós deixamos marcas [...] a gente deixa isso na vida das pessoas. Basicamente é pesquisar e estudar para ajudar as pessoas a se descobrirem como gente, a quererem ser mais gente. Ensinar implica primeiramente saber escutar, saber olhar, saber sentir, ou seja, reconhecer a pessoa com quem você vai trabalhar ensinando a aprender. [...] a nossa atividade de professores é uma atividade didático ou acadêmico-científica, mas, a nossa função é social e política. Se não tivermos clareza sobre o porquê nós queremos exercer social e politicamente a nossa função, nós não vamos achar os sentidos da nossa atividade (Professor Paulo).

[...] o que me marcou tanto [n]os projetos comunitários quanto [n]a educação superior é a relação com o estudante. Para mim, esse aspecto é fundamental, que a gente tem como professora. A construção desse vínculo, eu acho que esse é um elemento importante, quer dizer, pensar a aula a partir da turma que eu tenho. Sabe, esse semestre eu estou dando aula para essa turma. É na relação, eu vou estar me experimentando fazendo, mas, é nessa relação que a gente aprende a ser professora, pelo menos essa tem sido a minha experiência (Professora Vivian).

A minha bolsista, ela aceita ficar comigo para crescer, para participar, para estudar e para produzir. [...] ela vem para estudar, para fazer a sua formação, é um processo formativo. [...] Você tem que estar constantemente dialogando com seus pares (Professora Jaqueline).

Aqui precisa do desenvolvimento de um ser humano diferenciado, que tenha uma capacidade de escuta, capacidade de perceber o outro, a partir de onde o outro está (Professor Marlon). 
Os formadores ressaltam em suas falas a importância da atividade interpessoal assim como da rede de interação e mediação vivida nos espaços e tempos das aulas, reconhecendo que a formação do professor é uma interformação, do mesmo modo que a aprendizagem se dá em uma relação de reciprocidade. Logo, precisamos do outro para que as palavras tenham sentido para nós. Aprendemos na relação com o outro exatamente a partir dos aspectos que tanto nos aproximam quanto nos diferenciam. Esse ato é dialógico e marcado pela relação na alteridade, o que faz com que os pensamentos, as ações e as atitudes sejam vivenciados como eventos responsivos, únicos e singulares (AMORIM, 2004, 2009; BRAIT, 2005, 2014; FARACO, 2009; PONZIO, 2012; SOBRAL, 2010a, 2010b).

Compreendemos que as trajetórias formativas, vivenciadas na docência, expressam os sentidos desenvolvidos no processo de aprendizagem docente. Ao idealizarmos esse processo, a partir das relações construídas pelos formadores, consideramos que o olhar do outro e de si sobre o outro engendram novos sentidos valorativos sobre as ações docentes e, nesse movimento construtivo, ampliam-se e se configuram múltiplos sentidos sobre suas práticas.

Assim, podemos inferir que a docência é um processo de construção que envolve a troca e o compartilhamento entre os próprios sujeitos nos espaços formativos. Essa interação, que é social e cultural, implica na construção do conhecimento pedagógico compartilhado, que se realiza mediante processos de colaboração resultando em transformação (BOLZAN, 2009b).

Nesse sentido, o conhecimento pedagógico compartilhado promove experiências construtivas da docência, que devem ser continuamente repensadas e planejadas para que possam ser compartilhadas no coletivo da instituição e impliquem, significativamente, no DPD individual e grupal. Igualmente, o papel e a orientação pedagógica que o professor assume no seu fazer docente, desenvolvido no contexto institucional universitário, implicam na qualidade do conhecimento pedagógico que será compartilhado com seus alunos e colegas.

Nessa direção, os docentes se sentem instigados a refletir sobre os processos interformativos que caracterizam o contexto do trabalho pedagógico. Nas vozes dos formadores, o espaço e o tempo da aula no contexto universitário, caracterizado pela interação, promovem a aprendizagem docente, a partir dos saberes compartilhados na inter-relação entre formador e estudante. Tais perspectivas são explicitadas pelas seguintes narrativas:

Ninguém constrói conhecimento sozinho, mesmo quando eu me debruço em um livro eu já estou dialogando com uma infinidade de autores e trazendo para junto dessa interlocução com este autor ou com esta autora, todo um horizonte de compreensão que eu venho construindo com colegas, com estudantes, desde a educação básica, desde a graduação, na pós-graduação. Então, eu nunca sou eu isolado. Eu sou nós ensinando a aprender (Professor Paulo). 
É o mínimo para ser professora [...]. É fazer e refletir na prática e nessa relação, eu não consigo pensar ser professora sem ter uma turma, por exemplo, você precisa ter uma turma e é com essa turma que eu vou aprender a ser professora. Aprender com ela, ela vai me desafiar vai me fazer pesquisar, eu acho que ser professora é uma constante e não é nunca igual, eu não consigo pensar que é igual. Eu posso ter as mesmas disciplinas, mas nunca vai ser igual porque a relação com as turmas é que irá me dar essa dinâmica do ser professora (Professora Vivian).

Nessa direção, identificamos que os formadores têm consciência de que aprendem no espaço-tempo da aula por meio das relações interpessoais e dos conhecimentos compartilhados com os estudantes, da mesma forma, eles afirmam a importância do seu papel de mediador dos saberes ao se verem como responsáveis pela planificação das situações de ensino.

Essa consciência do formador implica na reflexão sobre os aspectos didático-pedagógicos e na qualidade das relações sociais que se estabelecem na aula, no âmbito da universidade. Dessa forma, ao considerar as vivências em atividades conjuntas, de apoio mútuo e colaborativo, como essenciais para a aprendizagem dos saberes da docência, o formador será capaz de avançar em seus processos intelectuais e concepções epistemológicas que favorecerão a diversificação e a qualificação das estratégias pedagógicas a serem implementadas no contexto das aulas.

Almeida nos auxilia a pensar no trabalho pedagógico como ação organizadora das atividades de ensino ao apontar:

Portanto, mais do que ações atomizadas aos encaminhamentos demandados pela prática, $o$ que importa numa perspectiva pedagógica que embasa essa ação formadora são as articulações desses elementos numa direção de sentido, que busque a ampliação e a contextualização dos conhecimentos, saberes e experiências dos sujeitos envolvidos na ação de ensinar e aprender - os professores e os alunos (2012, p. 99).

Consequentemente, as ações didáticas envolvidas no cotidiano do trabalho pedagógico são assumidas como exigências da docência e constituem-se em fatores que, ao serem problematizados, provocam a busca de processos formativos que se traduzem em aprendizagens que orientam o formador na tomada de decisão frente à atividade de ensino na formação inicial. Nesse sentido, o espaço vivencial da aula necessita caracterizar-se pela interlocução. Por meio desse processo dialógico dar-se-á a apropriação dos novos saberes tanto por parte do formador como do estudante em formação inicial.

Pimenta e Lima (2012) posicionam-se ao indicar que a sala de aula é um lugar de encontro entre professores e estudantes que carregam consigo suas histórias e marcas de vida, fatores indispensáveis aos processos de ensinar e aprender. Nesse sentido, evidenciamos nas narrativas dos formadores a preocupação e a reflexão acerca de diversificar as estratégias didático-pedagógicas a serem implementadas no trabalho pedagógico de acordo com as necessidades e características do estudan- 
te. Nessa contextura social, o formador está aprendendo a ser professor nas discussões produzidas em sala de aula e nas demandas que a atividade docente impõe:

Tem diferenças de dar aula para o diurno e para o noturno. A diferença é que a gente tem hoje muito mais um público trabalhador do que anos atrás, e isso implica no meu modo de dar aula, eu preciso levar em conta, no noturno principalmente, que eu trabalho com um público que já trabalhou de manhã e de tarde e que vem de noite para o terceiro. [...] então eu preciso pensar, eu preciso organizar uma aula muito mais dinâmica do que durante o dia, isso eu percebo a diferença [...] (Professora Vivian).

A realidade que nos circunda, ela nos posiciona, ela nos atinge, ela mexe conosco. Então, a sala de aula é um lugar público e o estudo individual é muito importante para você também continuar aprendendo e, sobretudo, momentos específicos de leitura coletiva, de discussão e debate coletivo, de reflexão e de desafios nos grupos. [...] minha prática educativa e da realidade social que nós estamos associados também, ela passa por diferentes fases, quer dizer, começa pelo desvelamento. [...] porque a consciência crítica, não quer dizer, necessariamente, um olhar negativo sobre a realidade (Professor Paulo).

Atualmente, estou trabalhando com os dois cursos, tanto diurno quanto noturno. Estou vendo a experiência como positiva no sentido de que os alunos têm um perfil diferente e eu acho que a gente está conseguindo de uma forma ou de outra contribuir com a formação deles, principalmente para mudar a realidade que eles estão inseridos, porque são alunos, na grande maioria do noturno, que já estão no mercado de trabalho (Professora Cristiane).

A construção de vínculos entre formadores e estudantes aparece nas narrativas como uma exigência da docência no ensino superior, pois, ao conhecerem as histórias de vida e as necessidades e expectativas dos estudantes com relação à formação inicial, esses formadores passam a (re)significar seu papel na mediação das aprendizagens e a considerá-lo na construção de saberes didático-pedagógicos capazes de inovar e qualificar o trabalho pedagógico.

Bolzan considera que "ao refletir sobre sua ação pedagógica, o professor estará atuando como um pesquisador da sua própria sala de aula [...] tornando-se, ele próprio, um produtor de conhecimento profissional e pedagógico" (2009a, p. 17). Assim, concebemos que ao olhar as atividades e atitudes vivenciadas na prática docente e ao refletir sobre elas, o professor encontrará o sentido para buscar elementos necessários à sua [trans]formação, os quais qualificam, fundamentalmente, a atuação docente.

Consideramos que a reflexão e a tomada de consciência sobre a complexidade da atividade docente possibilitam aos formadores ampliar e fortalecer sua autonomia intelectual, conscientizando-os de que os saberes da docência se constroem permanentemente, assim como os leva a se reconhecer como pesquisadores da sua própria prática. Desse modo, essas ações cognitivas, ao promoverem atitudes autônomas, qualificam a capacidade de fazer escolhas objetivas, responsáveis e 
verdadeiras, tanto no que diz respeito à organização do trabalho pedagógico como na aprendizagem de ser professor no curso da trajetória formativa (IMBERNÓN, 2009, 2011).

Nesse sentido, para que a aprendizagem docente aconteça ao longo dos diferentes ciclos de vida e da carreira profissional, é necessário que o formador se veja como uma pessoa em permanente situação de aprendizagem. Para isso, a consciência do inacabamento é considerada como uma condição sine qua non para que se promova o processo de (trans)formação na direção de qualificar os seus saberes e fazeres.

As narrativas expressam que os professores formadores estão conscientes desse processo e o valoram, ao explicitarem a sua concepção de aprendizagem no contexto da sua profissão. O que possibilita, no diálogo com os discursos, evidenciar a existência de ações autoformativas. As vozes dos professores manifestam esse sentido:

Aprender eu traduzo como produção do conhecimento. Produção no sentido de que eu não sabia algo e me aproprio de algo que não sabia. E esse algo ele só é apropriado porque há uma demanda, uma falta em mim como sujeito. O processo de produção do conhecimento tanto dos professores quanto dos estudantes na aula é algo especial e é completamente inesperado (Professora Liana).

[...] acho que eu preciso, devo e estudo porque o que me instiga a fazer isso é justamente porque eu compreendo o tanto que eu preciso disso. [...]. Então, eu tenho me sentido instigada a estudar hoje porque eu reconheço sim, que sou boa em alguns lugares e reconheço a minha fragilidade em outros (Professora Tailane).

[...] por mais que tu tenhas experiência, já sabe mais ou menos qual é a estrutura da disciplina; conhece o conteúdo que vai trabalhar, domina aquilo, tu estás sempre buscando [...]. Sempre faz uma releitura e outras questões aparecem e na sala de aula outras questões, às vezes, algumas que a gente não tinha se dado conta. Então, é um eterno e constante repensar e estudar sempre (Professora Francisca).

Nesse momento do mundo contemporâneo em que as mudanças acontecem numa velocidade nunca antes experimentada, o desafio é cotidiano. Então quando? Sempre, todo dia, todo momento, toda hora e a vida toda. Somente a leitura todos os dias, é tentar entender, ver o que outros pesquisadores apontam, problematizam, confrontam com aquilo que você pesquisa e tentar compreender os fenômenos (Professora Jaqueline).

Logo, os formadores reafirmam a necessidade contínua de estudar e pesquisar a fim de enfrentar os desafios vivenciados na educação superior. A consciência da inconclusão e a compreensão de que toda a aprendizagem sob o ensinar está associada a novas ações autoformativas possibilita a escolha de novos direcionamentos e percursos formativos. 
Nessa perspectiva, Freire (1996) salienta que a inconclusão é própria da experiência vital e que o homem é um ser inacabado, que está em constante transformação. Portanto, aprender a ser professor não se encerra na formação, mas continua por meio de enfrentamentos e exigências cotidianos que precisam ser superados. É importante, nesse processo, que o professor tome consciência da sua incompletude e se coloque como aprendente e ensinante, simultaneamente.

Assim, a necessidade de autoformação nasce de um movimento interno do docente, pois, para que se constitua professor, é necessário que esteja disposto a aprender, o que lhe incitará a mover-se em direção ao seu desenvolvimento profissional. Tanto o ensinar como o aprender pressupõem caminhos próprios que dependem das experiências e vivências de ser professor. Nessa direção, torna-se fundamental o professor ser protagonista da sua carreira e caminhar no sentido de uma autonomia intelectual, ou seja, ser um profissional com capacidade de fazer escolhas pessoais, respaldado pelos saberes teóricos e da experiência compartilhados nos espaços institucionais pelos quais transita (BOLZAN et al., 2016).

Desse modo, compreendemos que a autonomia requer um processo permanente de reconstrução, reelaboração e reflexão sobre suas ações docentes assim como enseja a consciência de que o espaço-tempo da aula configura-se em um encontro dialógico, cuja essência está em promover os movimentos reflexivos e de tomada de consciência sob o papel do professor.

Acreditamos que o encontro pedagógico vivenciado pelo professor/formador e o estudante sustenta-se na perspectiva de compartilhar significados e dar sentido às aprendizagens. Essa relação, ao ser construída durante o trabalho pedagógico, refletirá nos processos de ensinar e de aprender que se caracterizarão pelo entendimento de assumir a docência como uma atividade profissional fundamentada na ideia de rede colaborativa estabelecida pelos sentidos produzidos nas vivências formativas e pelo conhecimento compartilhado na relação interativa construída na alteridade.

\section{Apontamentos finais}

A reflexão sobre o conjunto das narrativas apresentadas neste estudo possibilita compreender que os formadores produzem sentidos na e da docência, à medida que subjetivam as experiências vivenciadas no contexto da profissão; valoram a tomada de consciência sob a opção por ser professor; compreendem os desafios e as exigências vividos no cotidiano da docência que implicam na organização do processo de ensino e aprendizagem no âmbito do trabalho pedagógico e, fundamentalmente, tomam consciência de que a constituição de ser professor é processual, interpessoal e contínua a partir do contexto institucional. 
Nessa direção, os sentidos expressos enfatizam que os elementos que constituem a aprendizagem docente desenvolvem-se em uma dinâmica dialeticamente articulada entre o contexto, a prática, a reflexão, as relações interpessoais e as ações formativas, o que nos permite destacar que, em suas trajetórias formativas, os formadores reconhecem, compreendem e valorizam que:

- o sentido da alteridade marca a consciência de que a aula, tomada como evento, é um espaço-tempo de interação formativa tanto para o professor/ formador como para o estudante, implicando na criação de vínculos interpessoais que contribuem para que o trabalho pedagógico atenda a necessidades, desafios e exigências da formação;

- a relação interpessoal é concebida no processo formativo como um sentido que singulariza e situa as decisões didático-pedagógicas necessárias ao desenvolvimento da práxis pedagógica profissional;

- a necessidade de conhecer o contexto sociocultural no qual os estudantes estão inseridos implica na organização do trabalho pedagógico;

- os processos interpessoais, na relação de alteridade, vivenciados no contexto da aula são desencadeadores de ações formativas que implicam na aprendizagem de saberes que capacitam o formador à tomada de decisão frente à atividade de ensino;

- a reflexão e a tomada de consciência acerca da complexidade da tarefa de formar, incidem no redimensionamento da dinâmica do trabalho pedagógico no espaço-tempo da aula e implicam no desenvolvimento da autonomia docente;

- as marcas da trajetória pessoal e profissional repercutem na construção da identidade do formador;

- as experiências na docência tornam-se vivências formativas porque promovem a tomada de consciência em relação à incompletude no âmbito pessoal e profissional.

Logo, consideramos que as trajetórias formativas vivenciadas pelos professores/formadores expressam os sentidos construídos no processo de aprendizagem docente, olhando-os a partir das relações estabelecidas no contexto sociocultural em que se desenvolvem e se articulam suas histórias de vida e de profissão.

A cada processo interativo, o olhar do outro e de si sobre o outro, em um dado espaço e tempo, engendram novos sentidos valorativos sobre as atividades docentes nas quais os professores estão envolvidos e, nesse movimento construtivo, ampliam-se e se configuram continuamente novos sentidos. 
Assim sendo, compreendemos que tanto os formadores quanto as IES necessitam planejar as atividades formativas, considerando a tessitura dos significados compartilhados e os sentidos subjetivados nas relações pedagógicas vividas nos processos de ensino e de aprendizagem. Esses sentidos configuram-se em indicadores para a sistematização e a criação de espaços e tempos contextualizados em redes colaborativas que promovam a aprendizagem docente.

\section{The learning teaching of the professor: guidelines in and of teaching in the context of the pedagogical work in higher education}

Abstract

This article discusses the teaching learning in academic education, analyzed from the categorical dimension of the senses produced in a professional context. As a goal, it is sought to understand the meanings produced in a teaching context of pedagogical work. Participants are teachers of undergraduate courses in Education (day and night) of a public Graduation Teaching Institution. This qualitative research was developed from the socio-cultural narrative approach. In the process of analyzing the findings it has been identified the meanings constructed, which indicate that the university classroom is a place of learning boosted by interpersonal relations; by knowledge of the social and cultural context of the student, which implies reflection on the pedagogical organization of teaching, and the self-actions and interformative experienced by trainers and produced fundamentally the idea of incompleteness, as are conceived as learning subjects. It is understood that both the trainers and the academic education institutions need to think the training activities, considering the fabric of shared meanings and subjectified directions in pedagogical relationships experienced in the teaching-learning processes. These senses shape on indicators that have repercussions in the planning and creation of the contextualized educational processes in collaborative networks in order to favor the professional development of teachers.

Keywords: College Education. Pedagogical work. Professional development. Teaching learning.

\section{Notas}

1 Para Tardif (2011, p. 38-39), os saberes disciplinares correspondem aos diversos campos do conhecimento, tais como se encontram hoje integrados na universidade sob a forma de componentes curriculares. Os saberes das disciplinas emergem da tradição cultural; os saberes curriculares dizem respeito aos discursos, objetivos, conteúdos e métodos a partir dos quais a instituição escolar categoriza e apresenta os saberes sociais; os saberes experienciais correspondem a saberes produzidos pelos próprios professores no exercício do seu trabalho cotidiano, ou seja, na prática da sua profissão.

2 Segundo Tardif, os saberes pedagógicos “apresentam-se como doutrinas ou concepções provenientes de reflexões sobre a prática educativa no sentido amplo do termo, reflexões racionais e normativas que conduzem a sistemas mais ou menos coerentes de representação e orientação da atividade educativa" (2011, p. 37). 
3 Projeto produtividade em pesquisa, Processo no 30.3485/2012-4 e Edital Universal MCTI/CNPq 14/20122015, Processo no 481.468/2012-9.

4 Bolzan e Powaczuk afirmam que o trabalho pedagógico compreende as "atividades direcionadas ao ensino e à aprendizagem, compondo, portanto, o trabalho docente. Esta compreensão está pautada nos estudos de Bolzan et al. (2010, 2013) que destaca o trabalho pedagógico relacionado aos processos envolvidos na prática docente em ação, envolvendo os modos de organização e reorganização das estratégias didáticas. Implica a reflexão e o constante redimensionar das ações pedagógicas desenvolvidas pelos docentes com o intuito de proporcionar a autonomia e a mobilização pela busca do saber" (2013, p. 2).

5 Garcia (1999, p. 19), baseado em Debesse (1982), afirma que autoformação é uma formação em que o indivíduo participa de forma independente e tendo sob o seu próprio controle os objetivos, os processos, os instrumentos e os resultados da própria formação.

6 Ações interformativas caracterizam-se pela busca de atividades conjuntas, em um sistema de cooperação. Há um evidente empenho, por parte dos sujeitos, de se desenvolverem e se aperfeiçoarem profissionalmente, o que implica um trabalho coletivo, centrado em interesses e necessidades comuns, indicando a cultura institucional como mote para esse processo (BOLZAN et al., 2016, p. 117).

7 Bakhtin redimensiona o termo arquitetônica, caracterizando-o "[...] não como um esquema abstrato, mas como o plano concreto do mundo do ato unitário singular, os momentos fundamentais da sua construção e da sua disposição recíproca. Estes momentos fundamentais são o 'eu para mim', o 'outro para mim' e o 'eu para o outro' todos os valores da vida real e da cultura se dispõem ao redor destes pontos arquitetônicos do mundo real do ato" (2012a, p. 114).

8 Processo que implica não só o domínio de conhecimentos/saberes/fazeres de determinado campo, mas também a sensibilidade do docente como pessoa e profissional em termos de atitude e valores, tendo a reflexão como componente intrínseco ao processo de ensinar, de aprender, de formar-se e, consequentemente, de desenhar sua própria trajetória, influenciado pela cultura acadêmica em contextos sociocultural e institucional concretos, nos quais os professores transitam (ISAIA; BOLZAN, 2007a).

9 Segundo Bakhtin, o excedente de visão significa "[...] entrar em empatia com esse outro indivíduo, ver axiologicamente o mundo de dentro dele tal qual ele o vê, colocar-me no lugar dele e, depois de ter retornado ao meu lugar, completar o horizonte dele com o excedente de visão que desse meu lugar se descortina fora dele" (2011, p. 23).

10 Para Bakhtin, o ato-evento é definido como o ato que "[...] não vê somente um contexto único, mas também o único contexto concreto, o contexto último, com o qual relaciona tanto o seu sentido, assim como, o seu fato, em que procura resolver responsavelmente a verdade única, seja do fato, seja do sentido, na sua unidade concreta" (2012a, p. 79).

${ }^{11}$ As reflexões advindas das narrativas sob a dimensão categorial dos sentidos na e da docência estão apoiadas nas análises e interpretações que compõem o relatório final do projeto interinstitucional e integrado Aprendizagem da docência: processos formativos de estudantes e formadores da educação superior (BOLZAN et al., 2016).

\section{Referências}

ALMEIDA, M. I. de. Formação de professor do ensino superior: desafios e políticas institucionais. São Paulo: Cortez, 2012.

AMORIM, M. O pesquisador e seu outro: Bakhtin nas ciências humanas. São Paulo: Musa, 2004. . Para uma filosofia do ato: "válido e inserido no contexto". In: BRAIT, B. (Org.). Bakhtin: dialogismo e polifonia. São Paulo: Contexto, 2009. p. 17-44.

BAKHTIN, M. A. Estética da criação verbal. 6. ed. São Paulo: Martins Fontes, 2011. . Para uma filosofia do ato responsável. 2. ed. São Carlos: Pedro \& João, 2012a. . (VOLOCHINOV, V. N). Marxismo e filosofia da linguagem. 13. ed. São Paulo: Hucitec, $2012 b$.

BOLZAN, D. P. V. Formação de professores: compartilhando e reconstruindo conhecimentos. 2. ed. Porto Alegre: Mediação, 2009a. 
Formação permanente e conhecimento pedagógico compartilhado: possibilidade na docência universitária. In: ISAIA, S. M. de A.; BOLZAN, D. P. V.; MACIEL, A. M. da R. (Org.). Pedagogia universitária: tecendo redes sobre a educação superior. Santa Maria: UFSM, 2009b. p. 131-148.

BOLZAN, D. P. V. et al. Aprendizagem da docência: processos formativos de estudantes e formadores da educação superior. Relatório parcial do projeto de pesquisa interinstitucional e integrado. Registro n⿳0 032835. Santa Maria: GAP/CE/UFSM, 2013.

. Aprendizagem da docência: processos formativos de estudantes e formadores da educação superior. Relatório parcial do projeto de pesquisa interinstitucional e integrado. Registro no

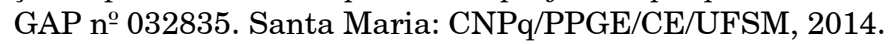

Aprendizagem da docência: processos formativos de estudantes e formadores da educação superior. Relatório final do projeto de pesquisa interinstitucional e integrado. Registro no GAP nํ0 032835. Santa Maria: CNPq/PPGE/CE/UFSM, 2016.

BOLZAN, D. P. V.; ISAIA, S. M. de A. Pedagogia universitária e aprendizagem docente: relações e novos sentidos da professoralidade. Revista Diálogo Educação, Curitiba, v. 10, n. 29, p. 13-26, jan./abr. 2010.

BOLZAN, D. P. V.; POWACZUK, A. C. H. Iniciação à docência universitária: a tessitura da professoralidade. Acta Scientiarum Human and Social Sciences, Maringá, v. 35, p. 201-209, jul./dez. 2013. Disponível em: <http://www.uem.br/acta>. Acesso em: 10 jul. 2015.

No prelo.

Processos formativos nas licenciaturas: desafios da e na docência. [S. 1.]: [s. n.], 2015.

BRAIT, B. Bakhtin e a natureza constitutivamente dialógica da linguagem. In: . (Org.). Bakhtin: dialogismo e construção do sentido. 2. ed. Campinas: Unicamp, 2005. p. 87-98.

. Análise e teoria do discurso. In: . (Org.). Bakhtin outros conceitos-chave. 2. ed. São Paulo: Contexto, 2014. p. 9-32.

CUNHA, M. I. A docência como ação complexa. In: . (Org.). Trajetórias e lugares de formação da docência universitária: da perspectiva individual ao espaço institucional. Araraquara: Junqueira \& Marin; Brasília: Capes/CNPq, 2010. p. 19-35.

Estudo um - Pressupostos do desenvolvimento profissional docente e o assessoramento pedagógico na universidade em exame. In: (Org.). Estratégias institucionais para o desenvolvimento profissional docente e as assessorias pedagógicas universitárias: memórias, experiências, desafios e possibilidades. Araraquara: Junqueira \& Marins Editores, 2014. p. 27-57.

FARACO, C. A. O problema do conteúdo, do material e da forma na arte verbal. In: BRAIT, B. (Org.). Bakhtin: dialogismo e polifonia. São Paulo: Contexto, 2009. p. 95-112.

FERRY, G. Pedagogia de la formación. Buenos Aires: Centro de Publicaciones Educativas y Material Didáctico, 2008.

FREIRE, P. Pedagogia da autonomia: saberes necessários à prática educativa. São Paulo: Paz e Terra, 1996.

GARCIA, M. C. Formação de professores: para uma mudança educativa. Porto: Porto Editora, 1999. 
HUBERMAN, M. O ciclo de vida dos professores. In: NÓVOA, A. (Org.). Vidas de professores. 2. ed. Porto: Porto Editora, 2000. p. 31-62.

IMBERNÓN, F. Formação permanente do professorado: novas tendências. São Paulo: Cortez, 2009 .

Formação docente e profissional: formar-se para a mudança e a incerteza. 9. ed. São Paulo: Cortez, 2011.

ISAIA, S. M. de A.; BOLZAN, D. P. V. Trajetória profissional docente: desafios à professoralidade. In: FRANCO, M. E. D. P.; KRAHE, E. D. Pedagogia universitária e áreas de conhecimento. Porto alegre: EdiPUCRS, 2007a. p. 107-118.

. Construção da profissão docente/professoralidade em debate: desafios para a educação superior. In: CUNHA, M. I. Reflexões e práticas em pedagogia universitária. Campinas: Papirus, 2007b. p. 161-178.

. Construção da profissão docente: possibilidades e desafios para a formação. In: ISAIA, S. M. de A.; BOLZAN, D. P. V.; MACIEL, A. M. R. (Org.). Pedagogia universitária: tecendo redes sobre a educação superior. Santa Maria: UFSM, 2009a. p. 163-176.

Trajetórias da docência: articulando estudos sobre os processos formativos e a aprendizagem de ser professor. In: ___ (Org.). Pedagogia universitária e desenvolvimento profissional docente. Porto Alegre: EdiPUCRS, 2009b. p. 121-144.

ISAIA, S. M. de A. Na tessitura da trajetória pessoal e profissional: a constituição do professor do ensino superior. In: ISAIA, S. M. A.; BOLZAN, D. P. V.; MACIEL, A. M. R. (Org.). Pedagogia universitária: tecendo redes sobre a educação superior. Santa Maria: UFSM, 2009. p. 95-106.

Trajetória pessoal/Trajetória profissional. In: MOROSINI, Marília Costa (Org.). Enciclopédia de Pedagogia Universitária. Glossário v. 2. Brasília: Inep, 2006. p. 368.

JOVCHELOVITCH, S.; BAUER, M. W. Entrevista narrativa. In: BAUER, M. W.; GASKELL, G. Pesquisa qualitativa com texto, imagem e som. 12. ed. Petrópolis: Vozes, 2014. p. 90-113.

LÜDKE, M.; ANDRÉ, M. E. D. A. Pesquisa em educação: abordagens qualitativas. 2. ed. Rio de Janeiro: EPU, 2013.

MARTINS FIGHERA, A.; BOLZAN, D. P. V. Ser pesquisador nas ciências do humano em diálogo com Bakhtin, Freire e Vygotski. Revista Memento, Betim, v. 5, n. 1, p. 1-15, jan./jun. 2014. Disponível em: <http://periodicos.unincor.br/index.php/memento/article/view/1586>. Acesso em: 8 maio 2016.

NÓVOA, A. Os professores e as histórias da sua vida. In: ed. Porto: Porto Editora, 2000. p. 11-30.

. (Org.). Vidas de professores. 2.

PIMENTA, S. G.; ANASTASIOU, L. G. C. Docência no ensino superior. 5. ed. São Paulo: Cortez, 2014.

PIMENTA, S. G.; LIMA, M. S. L. Estágio e docência. 7. ed. São Paulo: Cortez, 2012.

PONZIO, A. A revolução bakhtiniana. 2. ed. São Paulo: Contexto, 2012.

SOBRAL, A. Ato/atividade e evento. In: BRAIT, B. (Org.). Bakhtin: conceitos-chave. 4. ed. São Paulo: Contexto, 2010a. p. 11-36. 
. Ético e estético: na vida, na arte e na pesquisa em ciências humanas. In: BRAIT, B. (Org.). Bakhtin: conceitos-chave. 4. ed. São Paulo: Contexto, 2010b. p. 103-122.

TARDIF, M. Saberes docentes e formação profissional. 3. ed. Petrópolis: Vozes, 2011.

TARDIF, M.; LESSARD, C. O trabalho docente: elementos para uma teoria da docência como profissão de interações humanas. Tradução de João Batista Kreuch. 8. ed. Petrópolis: Vozes, 2013.

VAILLANT, D.; MARCELO, C. M. Ensinando a ensinar: as quatro etapas de uma aprendizagem. Curitiba: UTFPR, 2012.

VYGOTSKI, L. S. A formação social da mente. Tradução de José Cipolla Neto. São Paulo: Martins Fontes, 1994.

. Obras escogidas III. Madrid: Aprendizaje Visor Distribuciones, 1995.

A construção do pensamento e da linguagem. Tradução de Paulo Bezerra. 2. ed. São Paulo: Martins Fontes, 2009. 